CLINICAL STUDY

\title{
Early textural and functional alterations of left ventricular myocardium in mild hypothyroidism
}

\author{
Aghini-Lombardi Fabrizio $^{1}$, Di Bello Vitantonio ${ }^{2}$, Talini Enrica ${ }^{2}$, Di Cori Andrea ${ }^{2}$, Monzani Fabio ${ }^{3}$, \\ Antonangeli Lucia ${ }^{1}$, Palagi Caterina ${ }^{2}$, Caraccio Nadia ${ }^{3}$, Delle Donne Maria Grazia ${ }^{2}$, Nardi Carmela ${ }^{2}$, \\ Dardano Angela ${ }^{2}$, Balbarini Alberto ${ }^{2}$, Mariani Mario ${ }^{2}$ and Pinchera Aldo ${ }^{1}$ \\ ${ }^{1}$ Department of Endocrinology and Metabolism, ${ }^{2}$ Cardiac and Thoracic Department and ${ }^{3}$ Department of Internal Medicine, University of Pisa, \\ Via Paradisa 2, 56124 Pisa, Italy \\ (Correspondence should be addressed to F Aghini-Lombardi; Email: falombard@endoc.med.unipi.it)
}

\begin{abstract}
The aim of the present study was to evaluate cardiac function and texture in patients with subclinical hypothyroidism (sHT) both by conventional and new ultrasonic intramyocardial tissue techniques. sHT was characterized by normal serum free tetraiodotironine and free triiodotironine levels and slightly increased serum TSH level. Twenty-four patients affected by SHT and 24 sex- and age-matched healthy volunteers were studied. All subjects were submitted to conventional two-dimensional (2D)color Doppler echocardiography, pulsed wave tissue Doppler imaging (PWTDI) for the analysis of the diastolic function, color Doppler myocardial imaging (CDMI) for the analysis of regional strain and strain-rate and integrated backscatter (IBS) for the evaluation of intrinsic contractility and tissue characterization. The results of the present study were: (a) the detection in sHT subjects of a lower cyclic variation index (CVI) indicating an altered myocardial intrinsic contractility; (b) a higher ultrasonic myocardial reflectivity indicating an altered myocardial texture; (c) the detection of lower systolic strain and strain-rate indicating an alteration of myocardial regional deformability; (d) an initial impairment of left ventricular diastolic function indicated by a decrease of peak E mitral flow velocity and an increase of peak A mitral flow velocity. All parameters studied with conventional 2Decho in sHT patients were comparable with controls, except for a mild alteration in diastolic function. A significant correlation among systo-diastolic modifications detected by CDMI and IBS and serum TSH levels were found. The CVI at septum, the PWDTI S-peak wave and the systolic strain at septum were inversely related to the serum TSH levels. In conclusion, the new intramyocardial ultrasonic techniques confirm and extend the previous knowledge on the effect of the sHT on the heart, allowing the detection of early ultrastructural and regional functional systolic and diastolic abnormalities.
\end{abstract}

European Journal of Endocrinology 155 3-9

\section{Introduction}

Subclinical hypothyroidism (sHT) is an apparently asymptomatic condition defined by slightly increased serum thyroid-stimulating hormone (TSH) concentrations and normal free thyroid hormone levels $(1,2)$. As reported, in iodine sufficient areas, sHT occurs in $4-9.5 \%$ of the general population, being more frequent in women and in the elderly (3-5). In view of the minimal hormonal impairment and the apparent failure of symptoms, the need of a life-long treatment with levothyroxine (L-T4) is a matter of controversy. Nevertheless, this condition may be clinically relevant at level of target organs over a period of several years. Cardiovascular system is very sensitive to minimal defects of circulating thyroid hormones, and cardiovascular disorders are usually associated with overt hypothyroidism (6-8). Furthermore, the abnormalities in myocardial contractility and the changes of the lipoprotein profile that are frequently documented in hypothyroid patients have been reported $(6,8,9)$. Therefore, sHT may be considered a true risk factor for the development of coronary heart disease (6-13). Indeed, a progression of coronary angiographic lesions in untreated sHT patients in comparison with L-T4treated sHT patients has been reported (14).

Recently, it has been reported by an ultrasonic tissue characterization technique (videodensitometry) that sHT is associated with early abnormalities in both myocardial function and structure, which are reversible with replacement therapy $(15,16)$.

The aim of the present study was to evaluate heart function in patients with sHT, in otherwise cardiological healthy subjects, by a new intramyocardial ultrasonic technique, such as integrated backscatter (IBS) (17) for the evaluation of intrinsic contractility and tissue characterization, and color Doppler myocardial imaging (CDMI) $(18,19)$ for the analysis of regional myocardial 
strain and strain-rate. The advantage of both these methods is the independence of load condition and for strain also a relative independence from heart rotational and translational motions. Therefore, these techniques allow a very early diagnosis of systolic and diastolic dysfunction, when conventional echo-Doppler parameters of left ventricular function are still within normal range. In particular, both techniques correlate functional abnormalities with structural changes, such as the increased myocardial fibrosis, and left ventricular hypertrophy recently demonstrated in hypertension, in aortic stenosis and in acromegalic cardiomyopathy (20-22).

\section{Patients and methods}

\section{Subjects}

We studied 24 patients (19 women; mean age $34.8 \pm 6.3$ years) with newly untreated sHT. Mean serum-free thyroxine and free triodothyronine were $8.9 \pm 1.8$ and $3.5 \pm 0.7 \mathrm{pg} / \mathrm{ml}$ respectively. Mean serum TSH was $5.3 \pm 1.1 \mathrm{mU} / \mathrm{l}$ (normal range $0.4-3.4 \mathrm{mU} / \mathrm{l}$ ). In all patients, the etiology of SHT was chronic autoimmune thyroiditis, diagnosed by elevated circulating antiperoxidase and/or anti-thyroglobulin autoantibodies and diffuse hypoecogenicity by thyroid ultrasound. The inclusion criteria were age less than 45 years and slightly high serum TSH level ranging between 3.5 and $7.5 \mathrm{mU} / \mathrm{l})$. Patients with impairment of left ventricular systolic function (ejection fraction $<50 \%$ ), significant valvular heart disease, cardiomyopathy and diabetes mellitus were excluded. All sHT patients had normal blood pressure, normal level both of cholesterol (low- and high-density lipoprotein) and triglycerides and had a negative history for myocardial infarction or coronary artery disease. The control group included 24 sex- and age-matched healthy volunteers (19 women; mean age $30.8 \pm 6.7$ years). Cardiovascular and respiratory diseases were excluded in both patients and controls by a complete clinical work-up. Routine laboratory chemistry was normal in all, and none assumed any drug. Body mass index was 22.3 \pm 2.6 in controls and $24.5 \pm 3.0$ in sHT patients.

\section{Experimental procedure}

Hormonal and metabolic profile. Blood samples for free tetraiodotironine (FT4), free triiodotironine (FT3) and TSH evaluation were collected between 0800 and 0900 h. Serum FT4 and FT3 levels were measured using a chemiluminescent method (Vitros Eci-Ortho-Clinical Diagnostic Spa). The normal range was $7.0-17.0 \mathrm{pg} / \mathrm{ml}$ for FT4 and 2.7-5.7 pg/ml for FT3. Serum TSH level was determined by an ultra-sensitive chemiluminescent method (IMMULITE 2000-Diagnostic Products
Corporation analyzer) with a normal range of $0.4-$ $3.4 \mathrm{mU} / \mathrm{l}$. Determination of serum anti-thyroglobulin (Tg-Ab), anti-thyroperoxidase (TPO-Ab) was measured using an immunofluorescent method (AIA 21 TOSOHItalia). Diagnosis of sHT was based on the evidence of serum TSH level ranging between 3.5 and $7.5 \mathrm{mU} / \mathrm{l}$ and normal serum-free thyroid hormone levels.

Echocardiographic analysis. At the baseline, all the patients and controls were submitted to conventional echocardiography, pulsed wave tissue Doppler imaging (PWTDI), CDMI and acoustic densitometry. The operator was blinded of the subject's group.

Conventional 2D Doppler echocardiography. Conventional echocardiographic evaluation was performed as previously reported in detail $(15,16)$.

Pulsed wave tissue Doppler imaging (PWTDI). In the apical four-chambers view, the pulsed wave Doppler sample volume was subsequently placed in two different places of mitral annulus: septum and lateral wall. The apical fourchambers view was chosen to obtain a quantitative assessment of the global diastolic left ventricular function, almost simultaneously to the Doppler left ventricular inflow and to minimize the incidence angle between the Doppler beam and the longitudinal motion of mitral annulus $(23,24)$. PWTD of the septal annulus was used for the measurements of early peak diastolic mitral annulus velocity (Es). Left ventricular filling pressures were approximated from the relationship of $\mathrm{E} / \mathrm{Es}$ (E being derived by mitral flow velocity) (23).

CDMI derived-indices: Mean regional velocities, strain-rate and strain. CDMI data were offline analysed using a dedicated software (AMID, Florence, Italy). Velocity and strain-rate profiles were averaged over three cardiac cycles to derive mean velocity (VEL) and strain-rate curve averaged a mean RR interval. Mean natural strain $(\varepsilon)$ profiles and values were obtained integrating the mean strain profile by time using the AMID software. The frame rate ranged between 75 and $90 \mathrm{~Hz}$. A region of interest (ROI) consists in a myocardial segment bounded by four segments, two of them across the tissue and the other two parallel to the segment in a way that the enclosed area always contains the entire tissue segment during its movement. The software automatically recognizes the moving tissue inside the outlined area and the analysis is performed on the myocardial wall segment contained inside the area. In this way, the ROI becomes a responsive area that continuously follows the wall. The strain (computed from time-integration of the strain-rate) and the strainrate were calculated as reported $(18,19)$. 
Regional motion and the deformation in the longitudinal direction, both at medium posterior septum and medium lateral wall, were described by the following parameters calculated by apical chamber view: isovolumic relaxation time (VEL $\left.\mathrm{VLRT}_{\mathrm{IVR}}\right)$; isovolumic contraction time ( $\mathrm{VEL}_{\mathrm{IVCT}}$ ); maximum systolic velocity $\left(\mathrm{VEL}_{\mathrm{sys}}\right)$; early diastolic peak velocity $\left(\mathrm{VEL}_{\mathrm{E}}\right)$; late diastolic peak velocity $\left(\mathrm{VEL}_{\mathrm{A}}\right)$; maximum strain $\left(\varepsilon_{\mathrm{sys}}\right)$; maximum strain-rate $\left(\mathrm{SR}_{\mathrm{sys}}\right)$; early diastolic peak strainrate $\left(\mathrm{SR}_{\mathrm{E}}\right)$; late diastolic peak strain-rate $\left(\mathrm{SR}_{\mathrm{A}}\right)$. The intraclass correlation coefficient $\left(r_{i}\right)$ was calculated according to Bland and Altman's procedure (25). Three values of the strain-rate and strain were sampled for each patient and for each segment: septal and lateral; the correlation coefficient $\left(\mathrm{r}_{\mathrm{i}}\right)$ was 0.86 for septal and 0.89 for lateral segment, respectively.

Acoustic densitometry. High frame rate IBS imaging technology has been commercially applied to provide a more robust signal (calibrated in decibels, dB), with a substantial improvement of time-sequence of backscattered signal, further optimized for tissue characterization research. Acoustic densitometry measurement is independent from non-linear compression and postprocessing functions of the ultrasound imaging chain. The images were obtained using harmonic imaging mode. A detailed IBS methodology as previously described (21-23). Other important control settings of the imaging chain such as pre-processing, focus position, persistence, compression, high frame rate and post-processing were maintained constant for all patients, accurately avoiding the signal saturation (i.e. backscatter value sampled at the maximum value for the dynamic range of the system) at every level (pericardium, valve, myocardium) for possibility of estimation errors. End-diastolic IBS parameters $\left(\mathrm{IBS}_{\mathrm{ed}}\right)$ were then indexed for IBS pericardial values both at septum (IBS septumper $)$ and at posterior wall (IBS postwallper). The measurements obtained for each cardiac cycle were intensity of IBS at end-diastole $\left(\mathrm{IBS}_{\mathrm{ed}}\right)$, intensity of IBS at end-systole $\left(\mathrm{IBS}_{\mathrm{es}}\right)$. Cyclic variation index at septum $\left(\mathrm{CVI}_{\text {septum }}\right)$ and posterior wall level $\left(\mathrm{CVI}_{\text {posteriorwall }}\right)$, which were computed using the following formula: $\left.\left(\mathrm{IBS}_{\mathrm{ed}}-\mathrm{IBS}_{\mathrm{es}}\right) / \mathrm{IBS}_{\mathrm{ed}}\right) \times 100(23)$.

\section{Statistical analysis}

Continuous variables were expressed as mean \pm s.D. Student's $t$-test was used to quantitate variables among groups. The intraclass correlation coefficient $\left(r_{i}\right)$ was calculated according to Bland and Altman's procedure (25), using a one-way ANOVA for repeated measurements. Relation between two-dimensional (2D) echocardiographic measurements and TSH level were evaluated by terms of linear regression analysis. A $P$-value of $<0.05$ was considered significant.

\section{Results}

Clinical and hormonal data of sHT patients and controls are shown in Table 1. Systolic, diastolic mean blood pressure values, heart rate and body mass index (BMI) were comparable in both groups, remaining within the normal range. Serum TSH level was significantly higher in sHT patients than in controls $(P<0.001)$, while no differences were found in serum FT4 and FT3 levels. All patients with sHT had high level of Tg-Ab and/or TPO-Ab.

\section{Conventional echo-Doppler parameters}

Data derived from conventional echocardiographic analysis are summarized in Table 2. The septum and posterior wall thickness was significantly higher in SHT, while the left ventricular (LV) end-diastolic diameter was comparable. left ventricular mass $(\mathrm{LVM})_{\mathrm{bs}}$ was slightly but significantly higher in sHT, although still within the normal range. Cardiac output and systemic vascular resistances overlapped in both groups. With regard to LV systolic function, fractional shortening (FS) and ejection fraction (EF) values were within the normal range in both groups. Isovolumic contraction time was significantly higher $(P<0.01)$ in sHT patients than in controls. Pre-ejection period (PEP) was significantly higher in sHT patients in comparison with controls $(P<$ 0.05); as a consequence $\mathrm{PEP} /$ left ventricular ejection time (LVET) was significantly higher in sHT than in controls $(P<0.05)$. Left ventricular diastolic function showed a significant difference between sHT patients and controls due to decreased peak $\mathrm{E}(P<0.05)$ and increased peak A flow velocity, which was higher in sHT as compared with controls $(P<0.05)$. As a consequence, E/A ratio was significantly lower $(P<0.01)$ in sHT patients than in controls (Fig. 1, panel A). Isovolumic relaxation time (IVRT) was significantly higher in sHT compared with controls $(P<0.01)$.

Table 1 Clinical and hormone parameters in sHT patients and in controls.

\begin{tabular}{lccc}
\hline & $\begin{array}{c}\text { sHT }(\boldsymbol{n}=\mathbf{2 4}), \\
\text { mean } \pm \text { s.D. }\end{array}$ & $\begin{array}{c}\text { Controls }(\boldsymbol{n}=\mathbf{2 4}), \\
\text { mean } \pm \text { s.D. }\end{array}$ & $\boldsymbol{P}$ \\
\hline Age & $34.8 \pm 6.2$ & $33.9 \pm 6.4$ & $\mathrm{NS}$ \\
$\mathrm{BMI}$ & $22.33 \pm 2.6$ & $24.5 \pm 3.0$ & $\mathrm{NS}$ \\
SBP $(\mathrm{mmHg})$ & $117.2 \pm 9.9$ & $119.9 \pm 8.2$ & $\mathrm{NS}$ \\
DBP $(\mathrm{mmHg})$ & $73.2 \pm 5.6$ & $74.8 \pm 7.4$ & $\mathrm{NS}$ \\
$\mathrm{MBP}(\mathrm{mmHg})$ & $90.3 \pm 5.9$ & $92.9 \pm 10.5$ & $\mathrm{NS}$ \\
$\mathrm{HR}(\mathrm{b} / \mathrm{min})$ & $78.9 \pm 12.4$ & $75.9 \pm 11.7$ & $\mathrm{NS}$ \\
FT4 $(\mathrm{pg} / \mathrm{ml})$ & $8.9 \pm 1.8$ & $12.2 \pm 2.7$ & $\mathrm{NS}$ \\
FT3 $(\mathrm{pg} / \mathrm{ml})$ & $3.5 \pm 0.7$ & $3.9 \pm 3.4$ & $\mathrm{NS}$ \\
TSH $(\mu \mathrm{U} / \mathrm{ml})$ & $5.3 \pm 1.1$ & $1.4 \pm 0.8$ & $<0.001$ \\
\hline
\end{tabular}

BMI, body mass index; SBP, systolic blood pressure; DBP diastolic blood pressure; MBP, mean blood pressure; HR, heart rate. 
Table 2 Echo-Doppler conventional parameters in sHT patients and in controls.

\begin{tabular}{lccl}
\hline & $\begin{array}{c}\text { sHT }(\boldsymbol{n}=\mathbf{2 4}) \\
\text { mean } \pm \text { s.D. }\end{array}$ & $\begin{array}{c}\text { Controls }(\boldsymbol{n}=\mathbf{2 4}) \\
\text { mean } \pm \text { s.D. }\end{array}$ & $\boldsymbol{P}$ \\
\hline EDD $(\mathrm{cm})$ & $46.2 \pm 4.8$ & $48.2 \pm 4.7$ & $\mathrm{NS}$ \\
FS $(\%)$ & $42.8 \pm 5.3$ & $39.5 \pm 8.2$ & $\mathrm{NS}$ \\
EF $(\%)$ & $65.4 \pm 8.2$ & $62.5 \pm 9.5$ & $\mathrm{NS}$ \\
DSth $(\mathrm{mm})$ & $8.2 \pm 1.3$ & $9.8 \pm 1.4$ & 0.05 \\
DPWth $(\mathrm{mm})$ & $8.3 \pm 1.1$ & $9.5 \pm 1.6$ & 0.05 \\
LVM bs (g/m $\left.{ }^{2}\right)$ & $88.2 \pm 11.7$ & $98.5 \pm 12.1$ & 0.01 \\
EDV $\left(\mathrm{cm}^{3}\right)$ & $83.6 \pm 4.3$ & $86.3 \pm 6.5$ & $\mathrm{NS}$ \\
CO $\left(\mathrm{l} / \mathrm{min}^{2}\right)$ & $5.2 \pm 1.2$ & $5.3 \pm 1.3$ & $\mathrm{NS}$ \\
SPR & $1364.6 \pm 331.2$ & $1382.2 \pm 312.6$ & $\mathrm{NS}$ \\
Peak E (cm/sec) & $81.2 \pm 13.0$ & $71.2 \pm 15.7$ & 0.05 \\
Peak A (cm/sec) & $52.4 \pm 9.6$ & $67.5 \pm 10.7$ & 0.01 \\
E/A ratio & $1.5 \pm 0.3$ & $1.1 \pm 0.2$ & 0.02 \\
Mitral Dec time & $170.6 \pm 23.9$ & $143.6 \pm 34.6$ & 0.05 \\
(msec) & & & \\
IVRT (msec) & $71.3 \pm 10.5$ & $86.2 \pm 16.3$ & 0.01 \\
IVCT (msec) & $53.6 \pm 8.3$ & $63.5 \pm 12.5$ & 0.05 \\
LVET (msec) & $276.6 \pm 25.5$ & $279.6 \pm 25.9$ & $\mathrm{NS}$ \\
PEP (msec) & $80.6 \pm 10.8$ & $88.2 \pm 11.6$ & 0.05 \\
PEP/LVET & $0.28 \pm 0.05$ & $0.35 \pm 0.06$ & 0.02 \\
\hline
\end{tabular}

EDD, end diastolic diameter; FS, fractional shortening; EF, ejection fraction;DPW, diastolic posterior wall; LVM, left ventricular mass, EDV, end diastolic volume; $\mathrm{CO}$, cardiac output; SPR, systemic peripheral resistance; IVRT, isovolumetric relaxation time; IVCT, isovolumic contraction time;

LVET, left ventricular ejection time; PEP, pre-ejection period.

\section{Pulsed wave tissue Doppler imaging (PWTDI)}

Data derived from PWTDI are summarized in Table 3. The mean early diastolic peak velocity (PWTDI $E_{\mathrm{S}}$ and $\left.\mathrm{E}_{\mathrm{L}}\right)$ was lower in sHT patients than in controls $(P<0.01$ and $<0.03$ respectively); the late diastolic peak velocity $\left(\right.$ PWTDI $A_{S}$ and $A_{L}$ ) was higher in sHT patients than in controls $(P<0.03)$. The ratio between $\mathrm{E}$ and $\mathrm{A}$ velocities

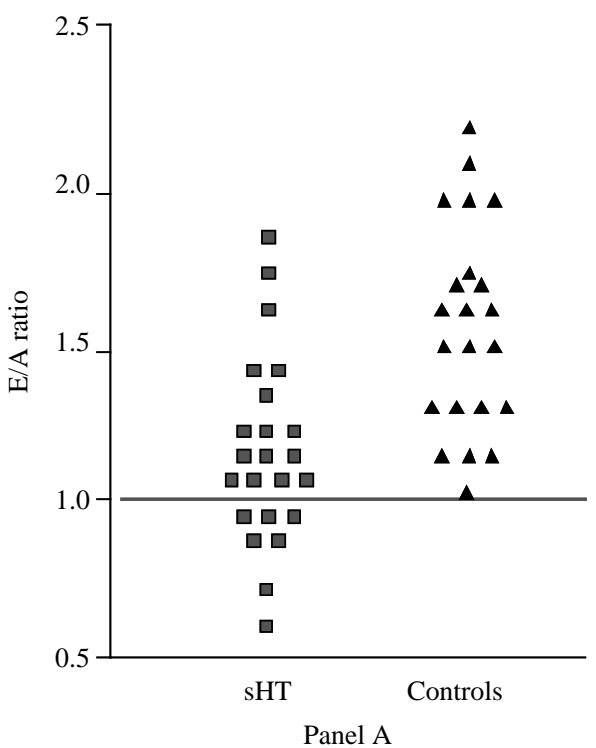

(PWTDI E/ $\mathrm{A}_{\mathrm{S}}$ and $\mathrm{E} / \mathrm{A}_{\mathrm{L}}$ ), expression of global diastolic left ventricular longitudinal function, was significantly lower in sHT patients than in controls $(P<0.04$ and $<$ 0.01 respectively). The PWTDI-IVRT both at septum and lateral wall annular level were significantly higher in sHT patients than in controls $(P<0.03$ and $<0.02$ respectively).

\section{CDMI-derived indices: mean regional velocities, strain-rate and strain}

The data of CDMI indices are also summarized in Table 4. The VELsys (S) and VELsys (L) were significantly lower in sHT patients in comparison with controls $(P<0.05$ and $<0.02$ respectively); the early mean diastolic regional velocity, both at medium septum and lateral wall level was lower in sHT patients than in controls $(P<0.01$ and $<0.05$ respectively); the late diastolic regional velocity, both at medium septum and lateral wall level was higher in sHT patients than in controls $(P<0.01$ and $<0.05$ respectively); the $\mathrm{VEL}_{\mathrm{E} / \text { Aratio }}$ was significantly lower in sHT patients than in controls $(P<0.01)$. The regional myocardial systolic strain findings evaluated both at medium septal and lateral wall level were significantly lower in sHT patients as compared with controls $(P<0.05$ and $<0.02$ respectively). The regional myocardial systolic strain-rate both at medium septal and lateral wall was significantly lower in sHT patients in comparison with controls $(P<0.05)$. When considering the diastolic $\mathrm{SR}$, the late phase was compromised in sHT patients as compared with controls $(P<0.05$ and $<0.02$ respectively).

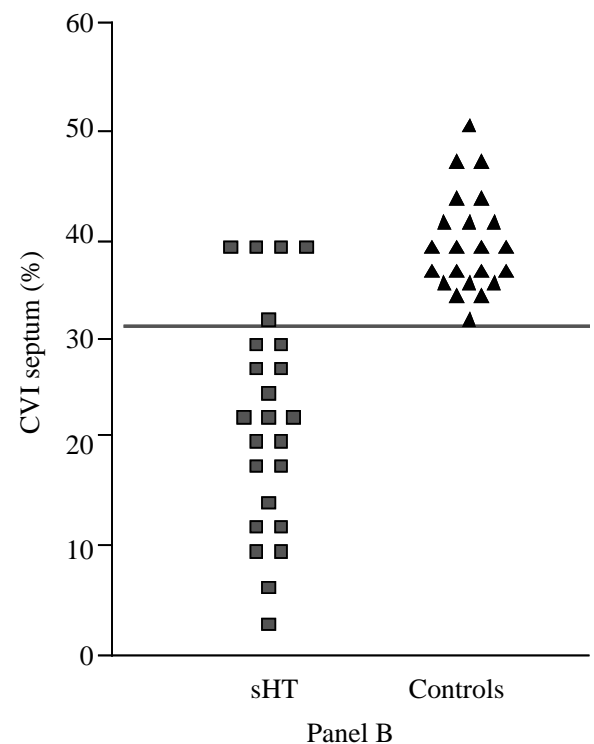

Figure $1 \mathrm{E} / \mathrm{A}$ ratio obtained by $2 \mathrm{D}$ conventional echocardiography (panel $\mathrm{A}$ ) and cyclic variation index at septum level obtained by integrated backscatter (panel B) in patients with subclinical hypothyroidism and in controls. 
Table 3 Pulsed wave tissue doppler imaging (PW-TDI) findings in sHT patients and in controls.

\begin{tabular}{lccc}
\hline $\begin{array}{l}\text { PWTDI } \\
\text { parameters }\end{array}$ & $\begin{array}{c}\text { sHT }(\boldsymbol{n}=\mathbf{2 4}) \\
\text { mean } \pm \text { s.D. }\end{array}$ & $\begin{array}{c}\text { Controls }(\boldsymbol{n}=\mathbf{2 4}) \\
\text { mean } \pm \text { s.D. }\end{array}$ & $\boldsymbol{P}$ \\
\hline PWTDI Ss & $8.0 \pm 1.1$ & $7.9 \pm 2.2$ & $\mathrm{NS}$ \\
PWTDI Es & $11.4 \pm 2.0$ & $9.8 \pm 2.7$ & 0.01 \\
PWTDI As & $7.7 \pm 1.7$ & $8.9 \pm 2.4$ & 0.03 \\
PWTDI E/As & $1.5 \pm 0.3$ & $1.1 \pm 0.2$ & 0.04 \\
PWTDI IVRTs & $74.4 \pm 9.2$ & $85.5 \pm 13.5$ & 0.03 \\
PWTDI SI & $10.6 \pm 2.1$ & $9.9 \pm 1.9$ & $\mathrm{NS}$ \\
PWTDI EL & $15.7 \pm 2.6$ & $13.9 \pm 3.5$ & 0.03 \\
PWTDI AL & $8.1 \pm 2.5$ & $10.3 \pm 4.3$ & 0.03 \\
PWTDI E/AL & $1.6 \pm 0.4$ & $1.2 \pm 0.5$ & 0.01 \\
PWTDI IVRTL & $73.6 \pm 10.3$ & $87.4 \pm 10.6$ & 0.02 \\
E/Es & $5.2 \pm 0.9$ & $5.6 \pm 2.1$ & $\mathrm{NS}$ \\
\hline
\end{tabular}

PWTDI Ss: peak of systolic velocity (S wave) at septal mitralic annulus level; PWTDI Es, early diastolic longitudinal peak velocity of mitral annulus at septum level; PWTDI As, late diastolic longitudinal peak velocity of mitral annulus at septum level; PWTDI IVRTs, isovolumic relaxation time of mitral annulus at septum level. PWTDIL, the same above cited parameters of velocity or time of mitral annulus sampled at lateral wall level. E/Es ratio between peak E transmitralic flow and PWTDI Es.

\section{Acoustic densitometry}

The main findings of backscatter parameters were also summarized in Table 4. CVI of both the septum (Fig. 1, panel B) and posterior wall level were significantly lower in sHT patients in comparison with controls

Table 4 Color Doppler Myocardial Imaging (CDMI) and Integrated Backscastter (IBS) findings in sHT patients and in controls.

\begin{tabular}{lrrl}
\hline CDMI parameters & & & \\
VEL sys (S) & $3.1 \pm 0.6$ & $2.4 \pm 0.8$ & 0.05 \\
VEL E (S) & $-4.9 \pm 1.2$ & $-5.9 \pm 1.0$ & 0.05 \\
VEL A (S) & $-2.8 \pm 1.0$ & $-4.5 \pm 1.8$ & 0.01 \\
VEL E/A (S) & $1.8 \pm 0.4$ & $1.1 \pm 0.4$ & 0.01 \\
Esys (S) & $-23.3 \pm 5.4$ & $-19.2 \pm 4.2$ & 0.05 \\
SR sys (S) & $-1.2 \pm 0.4$ & $-0.7 \pm 0.2$ & 0.05 \\
SR E (S) & $1.5 \pm 0.6$ & $1.0 \pm 0.4$ & 0.01 \\
SR A (S) & $0.6 \pm 0.4$ & $0.9 \pm 0.3$ & 0.05 \\
VEL sys (L) & $4.3 \pm 1.5$ & $3.0 \pm 1.1$ & 0.02 \\
VEL E (L) & $-5.4 \pm 1.3$ & $-4.2 \pm 1.6$ & 0.05 \\
VEL A (L) & $-2.5 \pm 1.2$ & $-3.4 \pm 1.3$ & 0.05 \\
VEL E/A (L) & $-2.1 \pm 0.8$ & $-1.6 \pm 0.7$ & 0.01 \\
ESys (L) & $-23.1 \pm 5.6$ & $-18.4 \pm 3.7$ & 0.02 \\
SR sys (L) & $-1.25 \pm 0.2$ & $-1.05 \pm 0.2$ & 0.05 \\
SR E (L) & $1.17 \pm 0.5$ & $1.09 \pm 0.4$ & NS \\
SR A (L) & $0.5 \pm 0.2$ & $0.8 \pm 0.3$ & 0.02 \\
IBS parameters & & & \\
CVI septum & $37.2 \pm 9.5$ & $22.6 \pm 10.2$ & 0.0001 \\
CVI post-wall & $42.5 \pm 8.6$ & $32.2 \pm 11.2$ & 0.001 \\
IBS septumper & $45.5 \pm 8.2$ & $53.8 \pm 7.3$ & 0.05 \\
IBS post-wallper & $43.5 \pm 6.9$ & $48.8 \pm 7.4$ & NS
\end{tabular}

CDMI parameters: VEL sys (S), peak of systolic regional velocity (S wave) at septum level; VEL E (S), early diastolic longitudinal regional peak velocity at septum level; VEL A (S), late diastolic longitudinal regional peak velocity at septum level; esys (S), regional systolic strain at septum level; SR sys (S), regional systolic strain-rate at septum level; SR E (S), early diastolic longitudinal regional systolic strain-rate at septum level; SR A (S), late diastolic longitudinal regional systolic strain-rate at septum level. (L), all the above cited parameters al regional lateral wall level. IBS parameters: CVI septum, cyclic variation index at septum level; CVI post-wall, cyclic variation index at posterior wall level; IBS septum per, ultrasonic reflectivity at septum level referred to pericardial interface reflectivity; IBS post-wall per, ultrasonic reflectivity at posterior wall level referred to pericardial interface reflectivity.
$(P<0.0001)$. The IBS values of the septum, indexed by pericardial interface, were higher than in controls $(P<0.05)$. No difference in IBS values of the posterior wall between sHT patients and controls were found. CVI at septum level $(P<0.001)$, the systolic strain at septum $(P<0.04)$ and at lateral level $(P<0.05)$ were related to TSH levels. CVI posterior wall was inversely related to TSH level $(P<0.01)$. In Fig. 2 is reported the correlation between CVI at septum and serum TSH level. In the present study, no relations among thyroid autoantibodies and CVI septum-(\%) and E/A ratio were found.

\section{Discussion}

The results of the present study indicate that backscatter ultrasonic non-invasive technique and CDMI allow to detect in SHT patients coexisting functional and textural abnormalities of the myocardium partially undetectable by conventional 2D-Doppler echocardiography. A large number of studies have been carried out to assess cardiac performance in sHT patients, but the results are conflicting (26-31), the question of whether sHT is related to risk for cardiovascular disease is controversial. These conflicting results may be explained by different selection of patients (number, age, type and length of sHT), different diagnostic criteria (range of TSH levels), different techniques and indexes used to assess cardiac performance. Our previous study showed that SHT is associated with early alterations in both myocardial function and structure as investigated by conventional echocardiography and videodensitometric analysis (15). Myocardial abnormalities were reversible by L-T4 replacement therapy (16).

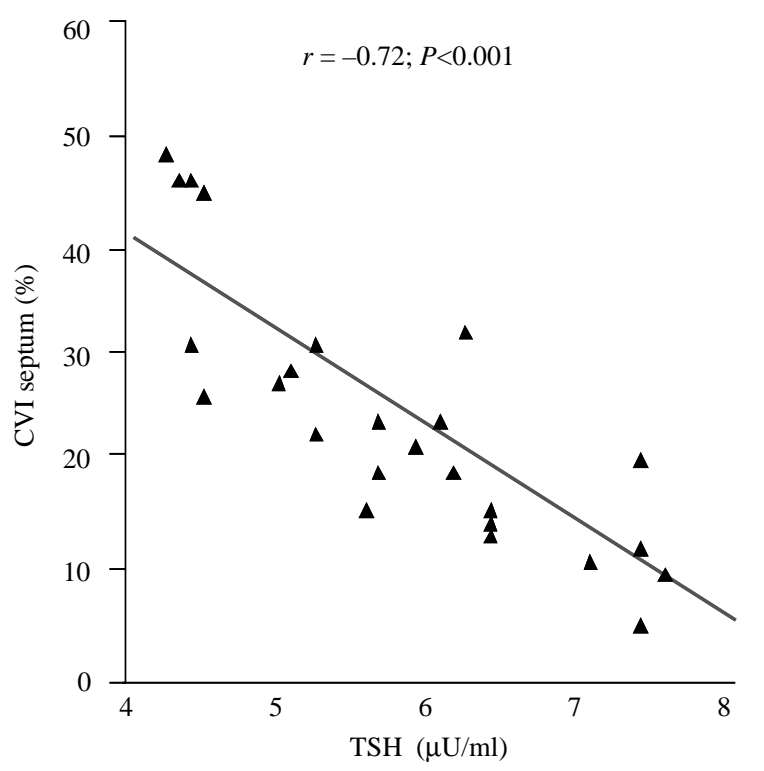

Figure 2 Relationship between cyclic variation index (CVI) at septum level and serum TSH level in patients with subclinical hypothyroidism (sHT). 
The present case-control study was carried out in a series of 24 young, otherwise healthy patients with untreated autoimmune sHT newly diagnosed and serum TSH ranging between 4.5 and $7.5 \mathrm{mU} / \mathrm{l}$. The intramural function and myocardial texture were investigated by acoustic densitometry with IBS technique and CDMI. The IBS technique is an evolution of the videodensitometric analysis, which allows a stronger characterization of the intrinsic myocardial contractility and texture (17). The CDMI allows the analysis of regional myocardial strain and strain-rate $(18,19)$. The advantages of these methods are the independence of load condition and for CDMI, the independence from heart rotational and translational motion.

In the present series of sHT patients, the results confirm and extends the impairment of both systolic and diastolic myocardial function previously described $(15,16)$, a lower CVI indicating a decreased myocardial intrinsic contractility and a high ultrasonic myocardial reflectivity suggesting an altered myocardial texture. The detection in sHT patients of a lower systolic strain and strain-rate analysis in comparison with controls suggests an alteration of myocardial regional deformability. Conventional echocardiographic indexes of left ventricular systolic function such as ejection fraction and fractional shortening are partially unable to differentiate healthy from sHT myocardium, while new ultrasonic systolic functional indexes have a high discriminating power between the two study groups. Among all new ultrasound parameters, the CVI at septum level showed the higher discriminating power (86\%) between groups, while conventional Doppler mitral flow E/A ratio showed a very low discriminating power $(33 \%)$ (comparison between the two methods, $P<0.001)$. In our previous study carried out in sHT patients by videodensitometric approach, a significantly lower CVI was found in sHT than controls (14).These subtle myocardial alterations were reversible after replacement L-T4 therapy (15). The L-T4 reversible cyclic variations of the echo amplitude in the face of normal load-dependent functional indexes, suggested that changes in CVI amplitude may be a distinct, early index of impaired intrinsic myocardial contractility $(15,16)$. Present data suggest that myocardial dysfunction in sHT is also associated with modifications of both the acoustic properties (IBS) and the velocity of myocardial fibres motion (CDMI). Several components can influence both the acoustic properties and the velocities of myocardial fibres, such as collagen, ventricular muscle fibres orientation, tissue albumin and water content, and capillary blood flow distribution $(6,21)$. The microstructural arrangement of myocardial cells embedded in a collagen matrix may provide a sufficient local acoustic impedance mismatch to account for the scattering from normal myocardium $(6,20)$.

Pulse wave tissue Doppler, as expression of global longitudinal left ventricular function, has already been used to identify left ventricular myocardial abnormalities in sHT. In fact, using PWTD, Vitale et al. (28) reported both an impairment of global longitudinal ventricular diastolic function and an alteration of myocardial time intervals, in patients with sHT. Zoncu et al. (29) demonstrated systolic and diastolic changes in patients with borderline hypothyroidism. Our study confirms the above-cited pioneering PWTD data and originally extends the observation of myocardial subclinical involvement in sHT status when studied by tissue characterization ultrasonic technique (IBS) and by CDMI, which allows the analysis of regional longitudinal strain and strain-rate. Previous tissue characterization study by videodensitometry documented high broad-band and higher volume collagen fraction - indicating increased intramyocardial fibrosis - only in overt, but not in subclinical hypothyroid patients (32). Minimal decrements in hormone activity at myocardial level may over time lead to biochemical and functional effects qualitatively similar to those of overt hypothyroidism, responsible for the functional myocardial alterations (6). These early alterations of myocardial function and texture, strengthen the opinion that sHT is strongly associated with risk for cardiovascular events (33). The role of thyroid autoimmunity in the development of cardiovascular events is still debated. In the present study, no relations among thyroid autoantibodies and CVI septum $-(\%)$ and $\mathrm{E} / \mathrm{A}$ ratio were found. These data suggest that the observed cardiac alterations were related to hypothyroidism, but independent from autoimmune phenomena (34).

In conclusion, present data confirm and extend the previous observation that both phases of heart cycle are early and contemporary involved in sHT causing the decrease of intramyocardial contractility and the impairment of both active and passive phases of diastole. The application of new sensible non-invasive techniques, which are more independent from load, rotational and translational heart motion, such as CDMI and IBS, allowed to detect subtle functional and textural alterations of intramural myocardium, partially undetectable by conventional 2D-Doppler echocardiography. Indeed, the high sensitivity of new ultrasonic intramyocardial indices of left ventricular global or regional function in comparison with conventional echo parameters may contribute to explain the different data of the literature regarding cardiac consequences of sTH.

\section{References}

1 Evered DC, Ormston EJ, Smith PA, Hall R \& Bird T. Grades of hypothyroidism. British Journal of Medicine 19731 657-662.

2 Surks MI, Ortiz E, Daniels GH, Sawin CT, Col NF, Cobin RH, Franklyn JA, Burman KD, Denke MA, Cooper RS \& Weissman NJ. Subclinical thyroid disease, Scientific review and guidelines for diagnosis and management. Journal of the American Medical Association $2004291228-238$. 
3 Tumbridge WMG, Evered DC, Hall R, Appleton D, Brewis M, Clark F, Grimley Evans J, Young E \& Bird T. The spectrum of thyroid disease in a community: the Whickham survey. Clinical Endocrinology (Oxford) 19777 481-493.

4 Sawin CT, Chopra D, Azizi F, Mannix JE \& Bacharach P. The aging thyroid, Increase prevalence of elevate serum thyrotropin levels in the elderly. Journal of the American Medical Association 1979242 247-250.

5 Canaris GJ, Manowitz NR, Mayor G \& Ridgeway EC. The Colorado thyroid disease prevalence study. Archives of Internal Medicine 2000 $160526-534$.

6 Kahaly GJ \& Dillmann WH. Thyroid hormone action in the heart. Endocrine Reviews 200526 704-728.

7 Toft AD \& Boon NA. Thyroid disease and the heart. Heart $2000 \mathbf{8 4}$ 455-460.

8 Klein J \& Ojamaa K. Thyroid hormone and the cardiovascular system. New England Journal of Medicine 2001344 501-509.

9 Sahin I, Turan N, Kosar F, Tascapan C \& Gunen H. Evaluation of autonomic activity in patients with subclinical hypothyroidism. Journal of Endocrinological Investgation 200528 209-213.

10 Forfar JC, Walhen CG, Todd TA, Bell GM, Hannan WJ, Muir AL \& Toft AD. Left ventricular performance in subclinical hypothyroidism. Quarterly Journal of Medicine 1985224 857-865.

11 Ridgway EC, Ladenson PW, Cooper DS, Daniels GH, Francis GS \& Maloof F. Cardiac function in mild and severe hypothyroidism. Life Science $198230651-658$.

12 Biondi B, Palmieri EA, Lombardi G \& Fazio S. Effects of subclinical thyroid dysfunction on the heart. Annals of Internal Medicine 2002 137 904-914.

13 Fazio S, Palmieri EA, Lombardi G \& Biondi B. Effects of thyroid hormone on the cardiovascular system. Recent progress in Hormone Research 200459 31-50.

14 Perk M \& O’Neill BJ. The effects of thyroid hormone therapy on angiographic coronary artery disease progression. Canadian Journal of Cardiology 199713 273-276.

15 Di Bello V, Monzani F, Giorgi D, Bertini A, Caraccio N, Valenti G, Talini E, Paterni M, Ferranini E \& Giusti C. Ultrasonic myocardial textural analysis in subclinical hypothyroidism. Journal of the American Society of Echocardiography 200013 832-840.

16 Monzani F, Di Bello V, Caraccio N, Bertini A, Giorgi D, Giusti C \& Ferranini E. Effect of levothyroxine on cardiac function and structure in subclinical hypothyroidism: a double blind, placebocontrolled study. Journal of Clinical Endocrinology and Metabolism 200186 1110-1115.

17 Holland MR, Wallace KD \& Miller JG. Potential relationships among myocardial stiffness, the measured level of myocardial backscatter ("image brightness") and the magnitude of the systematic variation of backscatter (cyclic variation) over the heart cycle. Journal of the American Society of Echocardiography 200417 1131-1137.

18 Edvardsen T, Gerber BL, Garot J, Bluemke DA, Lima JAO \& Smiseth OA. Quantitative assessment of intrinsic regional myocardial deformation by Doppler strain rate echocardiography in humans. Circulation 2002 $10650-56$.

19 Sutherland GR, DiSalvo G, Claus P, D’hooge J \& Bijnens B. Strain and strain rate imaging: a new clinical approach to quantifying regional myocardial function. Journal of the American Society of Echocardiography 200417 788-802.

20 Di Bello V, Giorgi D, Talini E, Dell'Omo G, Palagi C, Romano MF Pedrinelli R \& Mariani M. Incremental value of ultrasonic tissue characterization (backscatter) in evaluation of left ventricular myocardial structure and mechanics in essential arterial hypertension. Circulation $2003 \mathbf{1 0 7} 74-80$.

21 Di Bello V, Giorgi D, Viacava P, Talini E, Nardi C, Palagi C, Delle Donne MG, Verunelli F, Mariani MA, Grandjean J, Dell'Anna R, Di Cori A, Zucchelli G, Romano MF \& Mariani M. Severe aortic stenosis and myocardial function: diagnostic and prognostic usefulness of ultrasonic integrated backscatter analysis. Circulation $2004110849-855$.

22 Bogazzi F, Di Bello V, Palagi C, Delle Donne MG, Di Cori A, Gavioli S, Talini E, Cosci C, Sardella C, Brogioni S, Mariani M \& Martino E. Improvement of intrinsic myocardial contractility and cardiac fibrosis degree in acromegalic patients treated with somatostatin analogues: a prospective study. Clinical Endocrinology (Oxford) $200562590-596$.

23 Oki T, Tabata T, Yamada H, Wakatsuki T, Mishiro Y, Abe M, Onose Y, Iuchi A, Fukuda N \& Ito S. Left ventricular diastolic properties of hypertensive patients measured by pulsed Tissue Doppler Imaging. Journal of theAmerican Society of Echocardiography 199811 11061112.

24 Di Bello V, Giorgi D, Pedrinelli R, Talini E, Palagi C, Delle Donne MG, Zucchelli G, Dell'Omo G, Di Cori A, Dell'Anna R, Caravelli P \& Mariani M. Left ventricular hypertrophy and its regression in essential arterial hypertension: a Tissue Doppler Imaging study. American Journal of Hypertension 200417 882-890.

25 Bland JM \& Altman DG. Measurement error and correlations coefficients. British Medical Journal 1996313 341-342.

26 Arem K, Rokey R, Kiefe C, Escalante DA \& Rodriguez A. Cardiac systolic and diastolic function at rest and exercise in subclinical hypothyroidism: effect of thyroid hormone therapy. Thyroid 1996 6 397-402.

27 Biondi B, Fazio S, Palmieri EA, Carella C, Panza N, Cittadini A, Bonè F, Lombardi G \& Saccà L. Left ventricular diastolic dysfunction in patients with subclinical hypothyroidism. Journal of clinical Endocrinology and Metabolism $1999 \mathbf{8 4} 2064$ 2067.

28 Vitale G, Galderisi M, Lupoli GA, Celentano A, Pietropaolo I, Parenti N, de Vitis O \& Lupoli G. Left ventricular myocardial impairment in subclinical hypothyroidism assessed by a new ultrasound tool: pulsed tissue doppler. Journal of clinical Endocrinology and Metabolism 200287 4350-4355.

29 Zoncu S, Pigliaru F, Puzzu C, Pisano L, Vargiu S, Deidda M, Mariotti $\mathrm{S} \&$ Mercuro G. Cardiac function in borderline hypothyroidism: a study by pulsed wave tissue Doppler imaging. European Journal of Endocrinology 2005152 527-533.

30 Brenta G, Mutti LA, Schnitman M, Fretes O, Perrone A \& Matute ML. Assessment of left ventricular diastolic dysfunction by radionuclide ventriculography at rest and exercise in subclinical hypothyroidism, and its response to L-thyroxine therapy. American Journal of Cardiology 200391 1327-1330.

31 Holland MR, Wallace KD \& Miller JG. Potential relationships among myocardial stiffness, the measured level of myocardial backscatter ("image brightness") and the magnitude of the systematic variation of backscatter (cyclic variation) over the heart cycle. Journal of the American Society of Echocardiography 200417 1131-1137.

32 Ciulla M, Paliotti R, Tortora R, Valentini P, Cortelazzi B \& BeckPeccoz P. Myocardial ultrasonic reflectivity in patients with thyroid dysfunction: a tissue characterization study. Cardiovascular Imaging. $1997975-77$.

33 Bartalena L \& Pinchera A. Levothyroxine suppressive therapy: harmful and useless or harmless and useful? Journal of Endocrinological Investgation 199417 675-677.

34 Hak AE, Pols HAP, Visser TJ, Drexhage HA, Hofman A \& Witteman JCM. Subclinical hypothyroidism is an independent risk factor for atherosclerosis and myocardial infarction in elderly women: the Rotterdam study. Annals of Internal Medicine 2000132 270-278.

Received 17 January 2006

Accepted 29 March 2006 